\title{
Epileptogenesis Provoked by Prolonged Experimental Febrile Seizures: Mechanisms and Biomarkers
}

\author{
Céline M. Dubé, ${ }^{1,2}$ Teresa Ravizza, ${ }^{4}$ Mark Hamamura, ${ }^{3}$ Qinqin Zha, ${ }^{1,2}$ Andrew Keebaugh, ${ }^{1,2}$ Kimberly Fok, ${ }^{1,2}$ \\ Adrienne L. Andres, ${ }^{1,2}$ Orhan Nalcioglu, ${ }^{3}$ Andre Obenaus, ${ }^{5}$ Annamaria Vezzani, ${ }^{4}$ and Tallie Z. Baram ${ }^{1,2}$ \\ Departments of ${ }^{1}$ Anatomy and Neurobiology and ${ }^{2}$ Pediatrics, ${ }^{3} \mathrm{Tu}$ and Yuen Center for Functional Onco-Imaging, University of California, Irvine, Irvine, \\ California 92697, ${ }^{4}$ Department of Neuroscience, Laboratory of Experimental Neurology, Mario Negri Institute for Pharmacological Research, 20157 Milan, \\ Italy, and ${ }^{5}$ Department of Radiation Medicine, Loma Linda University School of Medicine, Loma Linda, California 92324
}

Whether long febrile seizures (FSs) can cause epilepsy in the absence of genetic or acquired predisposing factors is unclear. Having established causality between long FSs and limbic epilepsy in an animal model, we studied here if the duration of the inciting FSs influenced the probability of developing subsequent epilepsy and the severity of the spontaneous seizures. We evaluated if interictal epileptifom activity and/or elevation of hippocampal T2 signal on magnetic resonance image (MRI) provided predictive biomarkers for epileptogenesis, and if the inflammatory mediator interleukin-1 $\beta$ (IL-1 $\beta)$, an intrinsic element of FS generation, contributed also to subsequent epileptogenesis. We found that febrile status epilepticus, lasting an average of $64 \mathrm{~min}$, increased the severity and duration of subsequent spontaneous seizures compared with FSs averaging $24 \mathrm{~min}$. Interictal activity in rats sustaining febrile status epilepticus was also significantly longer and more robust, and correlated with the presence of hippocampal T2 changes in individual rats. Neither T2 changes nor interictal activity predicted epileptogenesis. Hippocampal levels of IL-1 $\beta$ were significantly higher for $>24 \mathrm{~h}$ after prolonged FSs. Chronically, IL-1 $\beta$ levels were elevated only in rats developing spontaneous limbic seizures after febrile status epilepticus, consistent with a role for this inflammatory mediator in epileptogenesis. Establishing seizure duration as an important determinant in epileptogenesis and defining the predictive roles of interictal activity, MRI, and inflammatory processes are of paramount importance to the clinical understanding of the outcome of FSs, the most common neurological insult in infants and children.

\section{Introduction}

Whether long febrile seizures (FSs) can cause epilepsy in the absence of genetic or acquired predisposing factors is unclear. This possibility is supported by the fact that many patients with temporal lobe epilepsy (TLE) have a history of long FSs without evidence of additional risk factors or a family history of epilepsy (Cendes et al., 1993; French et al., 1993; Shinnar, 1998; Theodore et al., 1999). The causal relationship of long FSs and TLE is clinically important, because, if it exists, then predictive biomarkers and preventive therapies might be feasible. To address this question, we have previously characterized an experimental model of long FSs in immature rodents (Dubé et al., 2000, 2005). Using this model, we found that experimental FSs lasting $\sim 20 \mathrm{~min}$, equivalent in duration to long childhood FSs, resulted in TLE in $\sim 35 \%$ of rats (Dubé et al., 2006). Because epilepsy does not arise spontaneously in naive rats, these experiments suggested that, at least in rodents, long FSs can provoke epileptogenesis in the absence of detectable predisposing factors.

If long FSs lead to epilepsy, then this process clearly takes place only in a minority of cases: FSs occur in $2-6 \%$ of children

Received Feb. 1, 2010; revised March 29, 2010; accepted April 16, 2010.

This work was supported by National Institutes of Health Grants NS35439 and R21 NS049618 (T.Z.B.), and EPICURE Grant LSH-CT-2006-037315 and Fondazione Monzino (A.V.). We thank Jennifer Abrahams for technical help and Dr. Bart Pollux for help with the statistics.

Correspondence should be addressed to Dr. Tallie Z. Baram, Departments of Anatomy/Neurobiology and Pediatrics, University of California, Irvine, Irvine, CA 92697-4475. E-mail: tallie@uci.edu.

DOI:10.1523/JNEUROSCI.0551-10.2010

Copyright $\odot 2010$ the authors $\quad 0270-6474 / 10 / 307484-11 \$ 15.00 / 0$
(Hauser and Hersdorffer, 1990; Berg et al., 1992; Stafstrom, 2002; Sillanpää et al., 2008) and are prolonged in 15\% (Nelson and Ellenberg, 1976; Maytal et al., 1989; Berg and Shinnar, 1996; Hesdorffer et al., 2008), suggesting that the incidence of prolonged FSs is $\sim 1: 300$ infants, whereas TLE is significantly less frequent (Nelson and Ellenberg, 1978; Annegers et al., 1987). If long FSs provoke TLE without predisposing factors, then why does this process take place only in some individuals? A plausible hypothesis involves differences in the duration or intensity of the inciting FSs themselves, a possibility that is supported by studies showing that epileptogenesis is found primarily in children with febrile status epilepticus (SE) (Annegers et al., 1987; Berg and Shinnar, 1996). Indeed, recent data suggest that the minimal seizure duration required for development of hippocampal magnetic resonance imaging (MRI)-apparent changes and EEG abnormalities is $\sim 55 \mathrm{~min}$ (VanLandingham et al., 1998; Scott et al., 2002, 2003; Natsume et al., 2007; Provenzale et al., 2008; Shinnar et al., 2008). If the duration or intensity of FSs governs epileptogenesis, then defining these parameters would help identify "at-risk" populations with better precision. Therefore, we conducted experiments to test if seizure duration predicted the probability of developing TLE and/or influenced its severity.

Because of the high prevalence of FSs and because relatively small numbers of individuals with prolonged FSs develop TLE, seizure duration alone may be a sensitive but not a specific marker of TLE. Therefore, we sought additional biomarkers for the epileptogenic process that might be useful for diagnostic clin- 
ical use. We focused on MRI because T2 signal changes have been described in children with long FSs, and on inflammation and especially interleukin- $1 \beta$ (IL-1 $\beta$ ) because it is intrinsically involved in the febrile response in children and in the generation of FSs in rodent models (Dubé et al., 2005).

\section{Materials and Methods}

Animals and generation of experimental prolonged FSs. Rats (males) were products of timed-pregnancy Sprague Dawley rats that were housed in an uncrowded, quiet animal facility room on a $12 \mathrm{~h}$ light/dark cycle and were provided with food and water ad libitum. Parturition was checked daily, and the day of birth was considered postnatal day 0 (P0). On P2, litters were adjusted to 10-12 pups, if needed. When weaned (on P21), rats were housed two to three per cage. Experimental procedures were approved by Institutional Animal Care Committees and conformed to National Institutes of Health guidelines. Supplemental Table 1 (available at www.jneurosci.org as supplemental material) describes the overall scheme of the experiments and the assignment of each rat.

Experimental long FSs were induced in rat pups $(n=51)$ on P11 as described previously (Baram et al., 1997; Dubé et al., 2000, 2006; Bender et al., 2003a). Two rats were placed in a glass jar and were subjected to a regulated airstream $\left(39.5-41^{\circ} \mathrm{C}\right)$ to raise their core temperature. Core temperatures were measured at baseline, at seizure onset (an average of $2.9 \mathrm{~min}$ from the onset of hyperthermia) (Dubé et al., 2007), and every 2 min during the seizures, and were maintained by moving rats that were close to the higher end of this range to cool surfaces for $2 \mathrm{~min}$. To examine if seizure duration influenced epileptogenesis, we increased the duration of hyperthermia (body temperature of $39.5-41^{\circ} \mathrm{C}$ ) to $70 \mathrm{~min}$, and the outcome was compared with that of the previous cohort exposed to 30-min-long hyperthermia (Dubé et al., 2006). The behavioral seizures induced by the hyperthermia have previously been correlated with EEG seizures (Baram et al., 1997) and were stereotyped, consisting of sudden movement arrest, followed by facial automatisms (chewing) and forelimb clonus, which might evolve to body flexion with biting of an extremity and rarely to generalized (tonic) seizures. After $70 \mathrm{~min}$ of hyperthermia, animals were weighed and moved to a cool surface until core temperature was reduced to the normal range for age $\left(34-35^{\circ} \mathrm{C}\right)$, and then returned to the dams. Control rats $(n=34)$ were littermates of the experimental group. They were separated from the dams for the same duration, and their core temperatures maintained within the normal range for age.

MRI procedure. Eighteen rats underwent MRI on postnatal day 10, to exclude any preexisting MRI-apparent lesions. Thirteen rats experienced experimental FSs $1 \mathrm{~d}$ later, and five were controls. Eleven of these rats were imaged 1 month later, and the same rats were then implanted with electrodes at 2 months and video-EEG monitored long-term for additional 10 months (see below). One FS rat died after a scan and a second lost his connector 1 month after surgery and was excluded from additional analysis.

Rats were sedated using isoflurane inhalation, maintained at $0.5-1 \%$ throughout the scan procedure. MRI scans were acquired with a 7 tesla, Oxford 300/150 horizontal magnet with an inner bore size of $150 \mathrm{~mm}$, as described previously (Dubé et al., 2009). Using 2D-MESE (twodimensional multi-echo-spin-echo sequence), the T2 sequence had the following parameters: repetition time, $3500 \mathrm{~ms}$; five echo times $(30,60$, 90, 120, $150 \mathrm{~ms}$ ); field of view, $38 \mathrm{~mm}$; a $256 \times 256$ matrix size; slice thickness, $500 \mu \mathrm{m}$; six averages for a total acquisition time of $2 \mathrm{~h}$. Twenty consecutive coronal slices with a gap of $100 \mu \mathrm{m}$ were obtained. Cuts of interest covered the brain from -6.5 to $-2.0 \mathrm{~mm}$ with reference to bregma (Paxinos and Watson, 1998). T2 relaxation time values (in milliseconds) were calculated on a pixel-by-pixel basis, and T2 maps were generated.

MRI analysis. Quantitative T2 relaxation maps were analyzed both on P10 and on P40. During this interval, brain maturation has profound effects on T2 values (Dubé et al., 2004); therefore, FS rats were compared with their littermate controls at each age. Regions of interest (ROIs) were manually outlined from T2-weighted images without knowledge of the experimental condition. The regions and the respective coordinates in- cluded the following: amygdala [basolateral and lateral nuclei combined, anteroposterior (AP), -2.2 to $-4.0 \mathrm{~mm}$; lateral (L), 4-5.5 mm], dorsal hippocampus (AP, -2.2 to $-4.0 \mathrm{~mm}$; $\mathrm{L}, 0.5-5 \mathrm{~mm}$ ), piriform cortex (AP, -2.2 to $-4.0 \mathrm{~mm}$; L $4-6.5 \mathrm{~mm}$ ), posterior hippocampus (AP, -4.6 to $-6.5 \mathrm{~mm}$; $\mathrm{L}, 1-6.5 \mathrm{~mm}$ ), entorhinal cortex (AP, -4.6 to -6.5 $\mathrm{mm}$; L, 5.5-7.5 mm), corpus callosum (AP, -2.2 to $-6.5 \mathrm{~mm}$ ), and external capsule (AP, -2.2 to $-6.5 \mathrm{~mm}$ ). For each ROI, T2 values for each rat that experienced long FSs were compared with the mean \pm SEM of the control group to determine the significance of any observed difference.

Electrode implantation. Animals underwent surgery 2 months ( $n=17$; $12 \mathrm{FS}$ and 5 controls) or 6 months ( $n=8 \mathrm{FS}$ and 4 controls) after the seizures. Rats were implanted with bipolar electrodes (Plastics One) bilaterally in the hippocampus [right hemisphere with the coordinates: AP, -3.7 ; L, 2.7; ventral (V), $-3.7 \mathrm{~mm}$; and left hemisphere with the coordinates: AP, $-5 ; \mathrm{L}, 5 ; \mathrm{V},-7.7 \mathrm{~mm}$ with reference to bregma] (Paxinos and Watson, 1998), and with one cortical electrode over the parietal frontal cortex (coordinates: AP, -2 ; L, $2 \mathrm{~mm}$, referring to bregma). One ground electrode was placed in the middle of the cerebellum. Three anchoring screws were placed over the cortex and dental acrylic was used to anchor the electrodes to the pedestal. Cortical and hippocampal recordings were conducted on freely moving rats.

Long-term digital video EEG recordings. After a week recovery period from the surgical procedure, experimental and control rats were recorded via a six-channel commutator (Plastics One) connected to bioamplifiers using Powerlab 8SP (ADInstruments) equipped with Chart 4 for Windows. The EEG recordings were synchronized with video monitoring using a commercial webcam (Logitech QuickCam, Ultra Vision; Logitech International). Bandpass frequency filters were set at 0.1 and $200 \mathrm{~Hz}$ with a sampling rate of $400 \mathrm{~Hz}$.

Digital video-EEG recordings were performed chronically for 10 months (in the group implanted at 2 months) or 5 months (in the group implanted at 6 months). Rats were recorded continuously for $24 \mathrm{~h}$ on fixed days twice a week for the first month, and for 48 consecutive hours once a week during the second month. At that point, we increased recordings to a continuous week once a month for 8 and 3 months, respectively. Rats were killed 2-30 d after the last recording. More than $6000 \mathrm{~h}$ of digital video-EEG recordings were obtained from rats that experienced long FSs $(5500 \mathrm{~h})$ and from control rats $(500 \mathrm{~h})$.

EEG analysis. Investigators unaware of the experimental group status analyzed the EEGs visually, scanning for seizures and for interictal activity. Electrographic seizures were defined as events consisting of polyspikes or sharp waves (amplitude, more than twofold background) that lasted >6 s (Nairismägi et al., 2004; Dubé et al., 2006) (see Fig. 2). Electrographic seizures were characterized by increasing amplitude and slowing frequency during seizure progression. Interictal events (see Fig. 3 ) were defined as follows: (1) polyspikes or sharp-waves discharges lasting $<5 \mathrm{~s}$; (2) isolated spikes and/or sharp waves; (3) spikes and/or sharpwave series. All the interictal events had an amplitude at least threefold higher than the background and, unlike seizures, were not correlated to changes in behavior. The videorecordings obtained concurrent with the EEGs were analyzed for behavioral manifestations of the apparent epileptiform discharges. We tested for typical behaviors associated with limbic seizures including sudden cessation of activity, facial automatisms, head bobbing, prolonged immobility with staring, alternating or bilateral clonus, rearing, and falling (Racine, 1972; Dubé et al., 2006). Both EEG and behavioral manifestations according to the above criteria were required to classify an event as a seizure. Rats were considered epileptic if they had at least one well documented seizure as defined above; $84 \%$ of epileptic rats had a minimum of two seizures, and $16 \%$ had one documented seizure.

Tissue harvesting and handling. For acute assessment of glia activation and IL- $1 \beta$ levels, 30 immature rats that sustained $\sim 60$-min-long FSs and 25 controls were killed $6,24,48$, or $72 \mathrm{~h}$ after the seizures $(n=4-8$ rats per group). Rats were either decapitated for Western blot analyses or deeply anesthetized with pentobarbital (Nembutal; $80 \mathrm{mg} / \mathrm{kg}$, i.p.) and perfused transcardially with $4 \%$ paraformaldehyde (PFA) in $0.1 \mathrm{M}$ phosphate buffer (PB), pH 7.4. Brains were removed, postfixed in 4\% PFA (90 $\min )$, cryoprotected in $30 \%$ sucrose $/ \mathrm{PB}(48 \mathrm{~h})$, and stored at $-80^{\circ} \mathrm{C}$. 
Immunocytochemistry. Coronal sections $(40 \mu \mathrm{m})$ were cut throughout the hippocampal formation into series using a cryostat, and every fourth and fifth sections from the dorsal hippocampus were processed for immunocytochemistry (ICC). Glial fibrillary acidic protein (GFAP) (a selective marker of astrocytes) and complement receptor type 3, OX 42 (a marker of macrophages/microglia), ICCs were performed on freefloating sections using standard avidin-biotin complex methods as described previously (Ravizza et al., 2006, 2008a,b). Briefly, sections were incubated at $4^{\circ} \mathrm{C}$ for $30 \mathrm{~min}$ in $0.4 \%$ Triton X-100 in PBS followed by a 15 min incubation in 3\% fetal bovine serum (FBS) in $0.1 \%$ Triton X-100 in PBS. The sections were subsequently incubated overnight at $4^{\circ} \mathrm{C}$ with mouse anti-rat monoclonal antibody against GFAP (1:2500 dilution; Millipore Bioscience Research Reagents) or CD11b (1:100 dilution; Serotec), in PBS containing 1\% Triton X-100 and 3\% fetal bovine serum. After rinsing in PBS, sections were incubated in biotinylated goat antimouse IgG (1:200; Vector Laboratories) for $1 \mathrm{~h}$ in PBS plus 4\% FBS. After washing, sections were incubated with avidin-biotin peroxidase complex (Vectastain ABC; Vector Laboratories) for $1 \mathrm{~h}$ at room temperature, and then incubated with 50\% 3,3'-diaminobenzidine (DAB) containing $0.009 \% \mathrm{H}_{2} \mathrm{O}_{2}$.

Isolectin $\mathrm{B}_{4}\left(\mathrm{BSI}-\mathrm{B}_{4}\right)$ was used as a specific marker of activated microglia because it recognizes $\mathrm{D}$-galactose-containing glycoconjugates expressed on the surface of activated (but not resting) microglial cells. ICC was conducted on free-floating sections as previously described (Streit and Kreutzberg, 1987; Ayoub and Salm, 2003) using isolectin $B_{4}$ peroxidase conjugate from Griffonia simplicifolia (Sigma-Aldrich). Sections were washed with $\mathrm{PBS}$ with $0.5 \% \mathrm{H}_{2} \mathrm{O}_{2}$ for $10 \mathrm{~min}$, rinsed with $\mathrm{PBS}$ with $0.1 \%$ Triton $\mathrm{X}-100$ for $5 \mathrm{~min}$, and incubated with isolectin $\mathrm{B}_{4}$ peroxidase conjugate (1:500) in PBS with $0.1 \%$ Triton X-100 at $4^{\circ} \mathrm{C}$ overnight. After rinsing with $\mathrm{PBS}$, sections were incubated with $50 \%$ DAB containing $0.009 \% \mathrm{H}_{2} \mathrm{O}_{2}$.

IL-1 $\beta$ ICC was performed on free-floating sections as described previously (Ravizza et al., 2008b). Sections were incubated $10 \mathrm{~min}$ in Trisbuffered saline (TBS) with $70 \%$ methanol and $2 \% \mathrm{H}_{2} \mathrm{O}_{2}$ followed by a solution of TBS containing 1\% Triton X-100 and 10\% FBS for $30 \mathrm{~min}$. Sections were incubated overnight at $4{ }^{\circ} \mathrm{C}$, with goat polyclonal anti-rat IL-1 $\beta$ (1:200; Santa Cruz Biotechnology) in TBS containing $1 \%$ Triton $\mathrm{X}-100,10 \% \mathrm{FBS}$. After rinsing in PBS, sections were incubated with rabbit anti-goat IgG (1:200; Vector Laboratories) for $1 \mathrm{~h}$ in $1 \%$ Triton X-100 TBS plus 10\% FBS. After washes, sections were treated as described above for GFAP and OX-42 ICCs.

Cell counts. Cell counts were performed on both perfused and frozen brains. Perfused brains included adult FS $(n=8)$ and control rats $(n=4)$ that were killed 11 months after the induction of the febrile status epilepticus. These rats were the same ones implanted 6 months after febrile SE and video-EEG recorded for 5 months. Rats were deeply anesthetized with pentobarbital ( $100 \mathrm{mg} / \mathrm{kg}$, i.p.) and perfused transcardially with $4 \%$ PFA in $0.1 \mathrm{M}$ PB. Brains were removed, postfixed in $4 \%$ PFA $(4 \mathrm{~h})$, cryoprotected in $30 \%$ sucrose/PB $(48 \mathrm{~h})$, and stored at $-80^{\circ} \mathrm{C}$. Frozen brains were derived from one brain hemisphere of rats implanted 2 months after febrile SE and video-EEG recorded for 10 months. For both groups, hippocampi were cut serially, and every 10th section was stained with $1 \%$ cresyl violet acetate. Counts were performed using stereological principles (Gundersen and Jensen, 1987), by an investigator unaware of the experimental group status of the sections (19 FS and 9 control rats). Areas for analysis were defined as follows (see Fig. 7A, schematic): For CA1 pyramidal cell layer, a grid was used and neuronal numbers were analyzed in two areas. The first area was defined by positioning the grid parallel to the hippocampal fissure laterally to the crest of CA1 toward CA3; the second area was analyzed by placing the grid the same way on the opposite side of CA1 crest. For CA3 pyramidal layer, neuronal numbers were also analyzed in two areas. The first area $\left(20,000 \mu \mathrm{m}^{2}\right)$ was defined by positioning the grid laterally parallel to the hippocampal fissure and to the superior blade of the granule cell (GC) layer, with its upper margin positioned along a virtual line connecting the tip of GC layer and the CA3/CA2 junction of the pyramidal cell layer. The second area $\left(20,000 \mu \mathrm{m}^{2}\right)$ was defined by placing an upper corner of the grid at the tip of GC layer suprapyramidal blade and the grid parallel to CA3 pyramidal cell layer. The hilus was defined by its borders with the granule cell layer and by an imaginary perpendicular line at the end of the CA3. Neurons located between this imaginary line and the GC layer were counted. Neurons were included when their nucleus and nucleolus were clearly identifiable. Counts were performed under $400 \times$ magnification. To account for potential volume change of the hippocampal formation after experimental long FSs, hippocampal volume was estimated in both experimental and control rats using Cavalieri's principles. Data were expressed as density (number of neurons per square millimeter) and as absolute number of neurons.

Western blot procedure and analysis. Western blot analyses of IL-1 $\beta$ were performed on immature rats (22 FS and 17 controls) (see supplemental Table 1, available at www.jneurosci.org as supplemental material). In addition, these analyses were performed on adult rats, nine experimental FS and five controls. These adult rats had been implanted 2 months after febrile SE and video-EEG recorded for 10 months (see supplemental Table 1, available at www.jneurosci.org as supplemental material), and one of their hemispheres was used for cell counts, as described above. Rats were decapitated, their brains were rapidly removed, and the hemispheres were separated and frozen on dry ice. Each sample consisted of a hippocampal extract from an individual rat. For regional analyses of protein expression in $\mathrm{CA} 1$, hippocampi were further dissected. Tissue was immediately frozen on dry ice and was homogenized in $20 \mathrm{~mm}$ Tris-HCl, pH 7.5, and $10 \mathrm{~mm}$ EDTA buffer containing complete protease inhibitor mixture (Complete; Roche). Equal amounts of protein $(150 \mu \mathrm{g})$ were separated by SDS-PAGE $(15 \%)$ and transferred to Hybond-P polyvinyl difluoride membranes (GE Healthcare). Membranes were rinsed with PBS containing $0.1 \%$ Tween 20 and blocked with $10 \%$ nonfat milk in $1 \times$ PBS overnight at $4{ }^{\circ} \mathrm{C}$. The membranes were probed with rabbit polyclonal anti-rat IL-1 $\beta$ (1:1500; Abcam) for $3 \mathrm{~h}$ at room temperature. After washes in PBS- $1 \%$ Tween (PBS-T), membranes were incubated with secondary anti-rabbit antibody (anti-rabbit; 1:10,000; GE Healthcare) in PBS with 5\% milk for $1.5 \mathrm{~h}$. Membranes were then washed repeatedly in PBS-T and incubated with ECL-Plus. Immunoreactive bands were visualized by apposing membranes to Hyperfilm ECL (GE Healthcare), and series of ECL exposures were performed to ensure that nonsaturated bands were used for quantification. Western blot data acquisition and analysis were accomplished by measuring the pixel density and area of immunoreactive bands from the ECL films using the NIH ImageJ software. Values were normalized to actin. Significance level for unpaired $t$ tests was set at 0.05 (Prism; GraphPad), and data are presented as mean with SEs.

Statistical analyses. Data are expressed as mean \pm SEM $(n=$ number of independent samples). Differences among groups were compared using one-way ANOVA with Bonferroni's post hoc analysis or Student's $t$ test as indicated (Prism; GraphPad). Significance was set at 0.05 .

\section{Results}

Experimental febrile seizure duration influences both the probability of developing limbic epilepsy and the severity/duration of the resulting spontaneous seizures

To test if seizure duration contributed to the probability of developing limbic (temporal lobe) epilepsy after experimental FSs, we modified our existing model to generate seizures lasting $\sim 60$ min (i.e., febrile status epilepticus). As shown in Figure $1 \mathrm{~A}$, the threshold to the generation of these FSs was $40.4 \pm 0.1^{\circ} \mathrm{C}$, in accord with our previous work on shorter experimental FSs, and seizures lasted $64.3 \pm 0.5 \mathrm{~min}$. Notably, the duration of hyperthermia was not longer than that of many febrile episodes in children (Shinnar et al., 2008) and did not result in dehydration: Rat weights immediately before seizures averaged $24.3 \pm 0.4 \mathrm{~g}$, and immediately after the seizures, $23.6 \pm 0.4 \mathrm{~g}$ (Fig. $1 \mathrm{~B}$ ), a weight change of $3.09 \pm 0.3 \%$. In children, clinically mild dehydration is defined as $>5 \%$ of body weight loss, whereas moderate to severe dehydration exceeds 10 and $15 \%$ weight loss, respectively (Portale et al., 2002). The temperature profile of rats experiencing these longer FSs ranged from $<39.5$ to $40.8^{\circ} \mathrm{C}$ (Fig. $1 C$ ), in accord with our findings on shorter seizures, and well within 

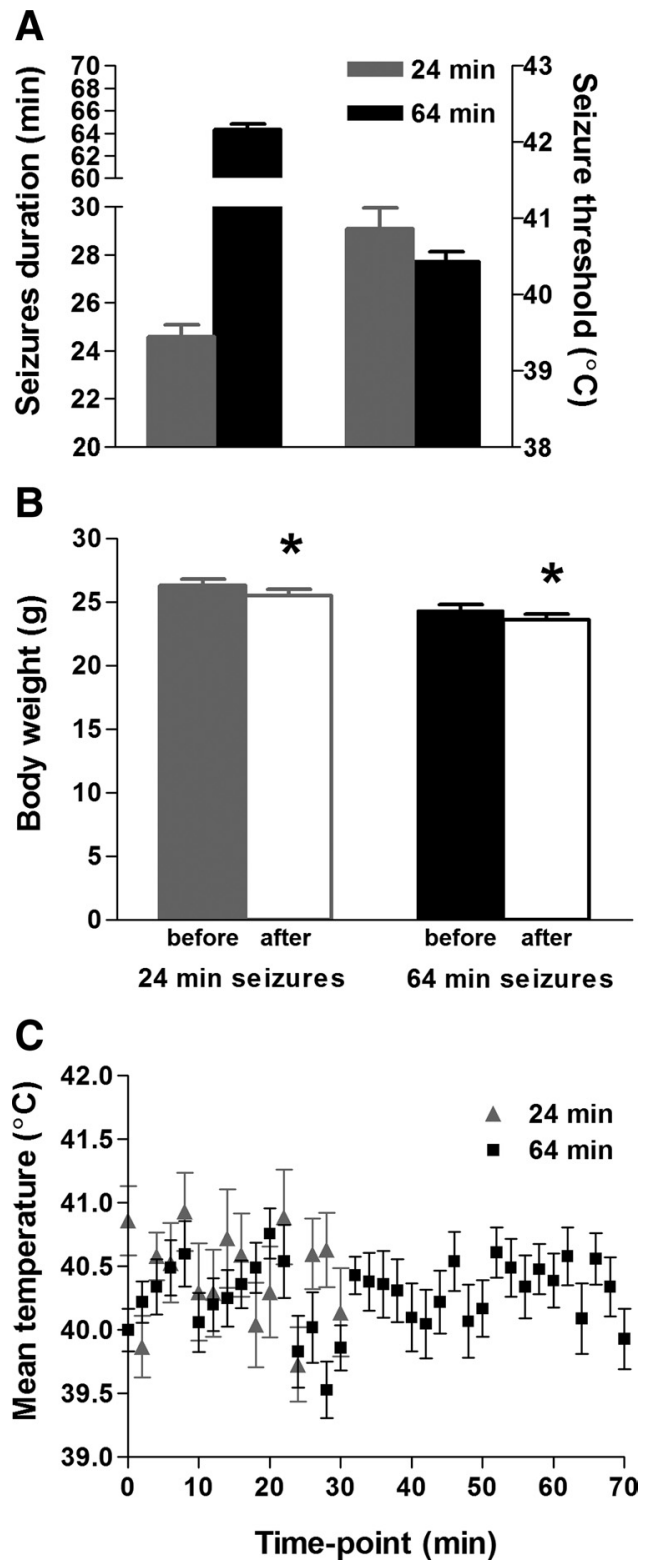

Figure 1. Parameters of experimental FSs lasting 24 or $64 \mathrm{~min}$. A, Duration of seizures on 30 or 70 min of hyperthermia (left $y$-axis) and threshold temperatures in both paradigms (right $y$-axis). $\boldsymbol{B}$, Rats were weighed before and after 30 or 70 min hyperthermia epochs; average weights before and after the seizures differed by $<3 \%$. This indicates that the rats did not suffer from dehydration. $C$, Average core temperatures throughout the 30 or 70 min of hyperthermia fluctuated between 39.5 and $40.8^{\circ} \mathrm{C}$. Error bars indicate SEM. ${ }^{*} p<0.05$.

the range found in febrile children (el-Radhi et al., 1986; Berg et al., 1992), and much lower than temperatures associated with heat stroke (Dematte et al., 1998; Jardine, 2007) or malignant hyperthermia (Hopkins, 2000; Rosenberg et al., 2007). Together, the above results indicated that it was feasible to generate experimental febrile seizures simulating childhood febrile SE, of the type that has been associated with subsequent MRI and EEG changes (Shinnar et al., 2008).

We then queried if the longer seizure duration augmented the probability of developing spontaneous limbic seizures (TLE) and if the severity of the resulting epilepsy depended on the inciting seizure. As shown in Figure $2 A$, rats experiencing a 24-min-long "FS" had a 35\% probability of developing epilepsy (Dubé et al., 2006). In comparison, $45 \%$ of rats experiencing a $64 \mathrm{~min}$ febrile
A
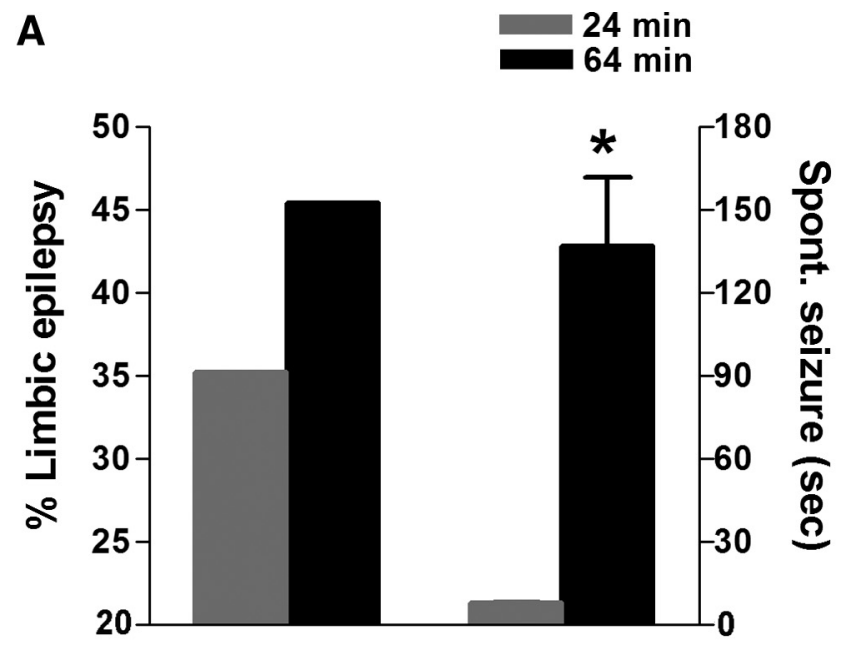

B

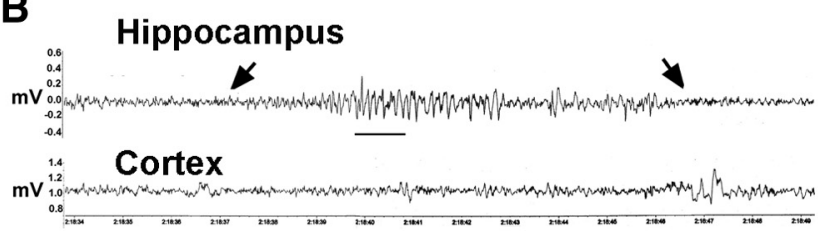

C

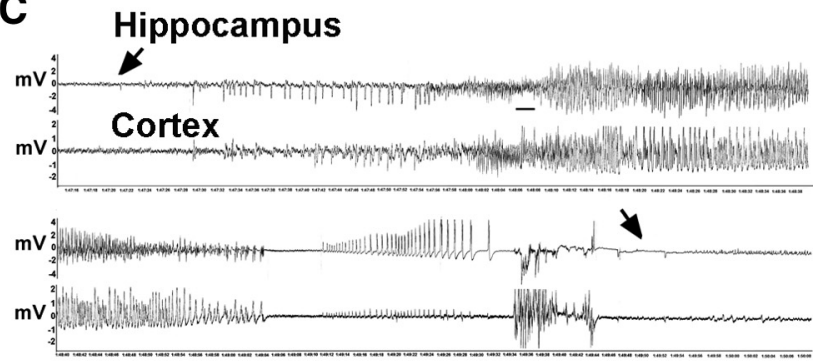

D
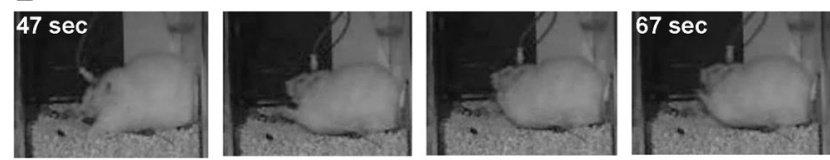

Figure 2. A 64 min FS increased the severity of the resulting epilepsy compared with a 24 min seizure. $A$, The percentage of rats developing limbic epilepsy increased by $30 \%$ after a 64 $\mathrm{min} F \mathrm{~S}$ compared with a $24 \mathrm{~min} F$. The duration of FSs affected the duration and the severity of the resulting spontaneous seizures: Mean duration of seizures was significantly longer

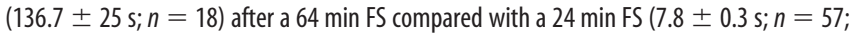
median durations, 91 vs 7 s). $\boldsymbol{B}, \boldsymbol{C}$, Typical spontaneous electrographic seizures recorded from hippocampal and cortical bipolar electrodes in adult rats that had sustained $24(\boldsymbol{B})$ or $64 \mathrm{~min}(\boldsymbol{C})$ FS. The arrows point to onset and end of epileptiform discharges. Note the clear development of epileptiform cortical discharges in seizures arising after a $64 \mathrm{~min} F \mathrm{~S}$, compared with suppression of cortical EEG amplitude observed in seizures that arose after a 24 min FS. Calibration: $1 \mathrm{~s}$. $D$, Still images from a video of a spontaneous seizure resulting from a $64 \mathrm{~min} \mathrm{FS}$ : The seizure consisted of alternating and bilateral clonus accompanied by facial automatisms. ${ }^{*} p<0.05$. Error bars indicate SEM.

SE developed spontaneous seizures $\left(p^{2}=0.54 ; \mathrm{df}=1 ; p=0.46\right)$. The duration of the resulting epileptic seizures was significantly influenced by the inciting FSs. Whereas limbic epilepsy after a 24 min FS resulted in seizures averaging $8 \mathrm{~s}$ (median, $7 \mathrm{~s} ; n=57$ ), the mean duration of spontaneous seizures generated by a $64 \mathrm{~min}$ febrile SE was $137 \mathrm{~s}$ (median, $91 \mathrm{~s} ; n=18 ; p<0.05$ ) (Fig. $2 A$ ). The behaviors during the epileptic seizures varied as a function of the FS duration. Behavioral seizures after a $24 \mathrm{~min}$ FS consisted of 
sudden cessation of activity accompanied by facial automatisms (stage 1) (Racine, 1972), whereas the behavioral seizures in rats that experienced a $64 \mathrm{~min}$ febrile SE progressed to head bobbing, alternating or bilateral clonus, rearing and falling (stages 2-5) (Racine, 1972). In addition, the amplitude of the epileptiform EEG discharges during the seizures generated by the 64 min FS $(0.93 \pm 0.18 \mathrm{mV}$ during the second second of the seizure; $2.43 \pm$ $0.23 \mathrm{mV}$ during the penultimate second; $N=18$ ) was significantly higher than the amplitude of discharges in seizures generated by a $24 \mathrm{~min}$ FS $(0.186 \pm 0.006$ and $0.41 \pm 0.012$, respectively; $N=57 ; p<0.01$ for both). Regardless of the duration of the original FSs, the resulting spontaneous seizures appeared to emerge from the limbic circuit, commencing in the hippocampus before propagating to the cortex (Fig. $2 B, C$ ). In epilepsy generated by a 64 min FS, epileptiform cortical discharges were apparent, whereas propagation in the 24 min epilepsy model consisted of attenuation of cortical EEG amplitude.

\section{The relationship of interictal EEG parameters and epileptogenesis}

In both children (Frantzen et al., 1968; Shinnar et al., 2007) and rodents (Dubé et al., 2006), long FSs can provoke changes in the interictal EEG. However, whether or not these interictal changes are predictive of eventual development of spontaneous seizures is not fully understood. Therefore, we analyzed the EEGs of rats exposed to $70 \mathrm{~min}$ of hyperthermia, starting at 2 or 6 months after experimental FSs $(n=19)$ and compared them with those of age-matched controls $(n=9)$. In addition, we compared EEGs from rats that eventually developed epilepsy with those that did not. Interictal events after a $24 \mathrm{~min}$ FS often consisted of isolated spikes and sharp-wave bursts (Dubé et al., 2006), whereas typical interictal activity after a $64 \mathrm{~min}$ febrile SE consisted of isolated spikes as well as spike or sharp-wave series (Fig. $3 A$ ). Interictal activity in both groups emanated from bipolar leads in hippocampus and cortex or the hippocampus alone, and was not observed in $>500 \mathrm{~h}$ of recording from control rats. There was no significant difference in the proportion of rats that developed interictal events after 24 vs 64 min experimental FSs [ 15 of 17 $(88.2 \%)$ vs 16 of $19(84.2 \%)]$. In both groups, more than twice as many rats developed such activity compared with those that eventually had spontaneous seizures. Whereas no rat became epileptic without interictal activity, the mere presence of such activity was a poor predictor of frank epileptogenesis. In rats experiencing a $24 \mathrm{~min} \mathrm{FS}$, interictal events tended to be short and numerous, as apparent from the analysis of the number of interictal events per recorded EEG hour and the mean duration of each interictal event (Fig. 3B). In contrast, interictal events, typically spike series, from rats that had sustained $64 \mathrm{~min}$ febrile SE were less frequent but much longer. Therefore, the average total time spent in interictal activity (number of events multiplied by their duration, in seconds per hour) was significantly higher in rats experiencing the $64 \mathrm{~min}$ FS $(20.6 \pm 1.3 \mathrm{~s} / \mathrm{h})$ compared with the $24 \mathrm{~min}$ group $(3.08 \pm 0.1 \mathrm{~s} / \mathrm{h})$. However, similar to the presence of interictal activity, the duration of this activity did not help predict the development of epilepsy and did not distinguish rats that became epileptic from those that did not (Fig. 3C). For example, after a 64 min FS, average duration of interictal events did not distinguish epileptic from nonepileptic rats $(131.4 \pm 49.42$ and $123.6 \pm 16.79 \mathrm{~s} ; p=0.86)$, and the frequency of interictal events (number per hour) was similar $(0.18 \pm 0.07$ in epileptics vs $0.14 \pm 0.06$ in nonepileptics; $p=0.68$ ). Thus, the average time in interictal activity per hour was not significantly longer in rats
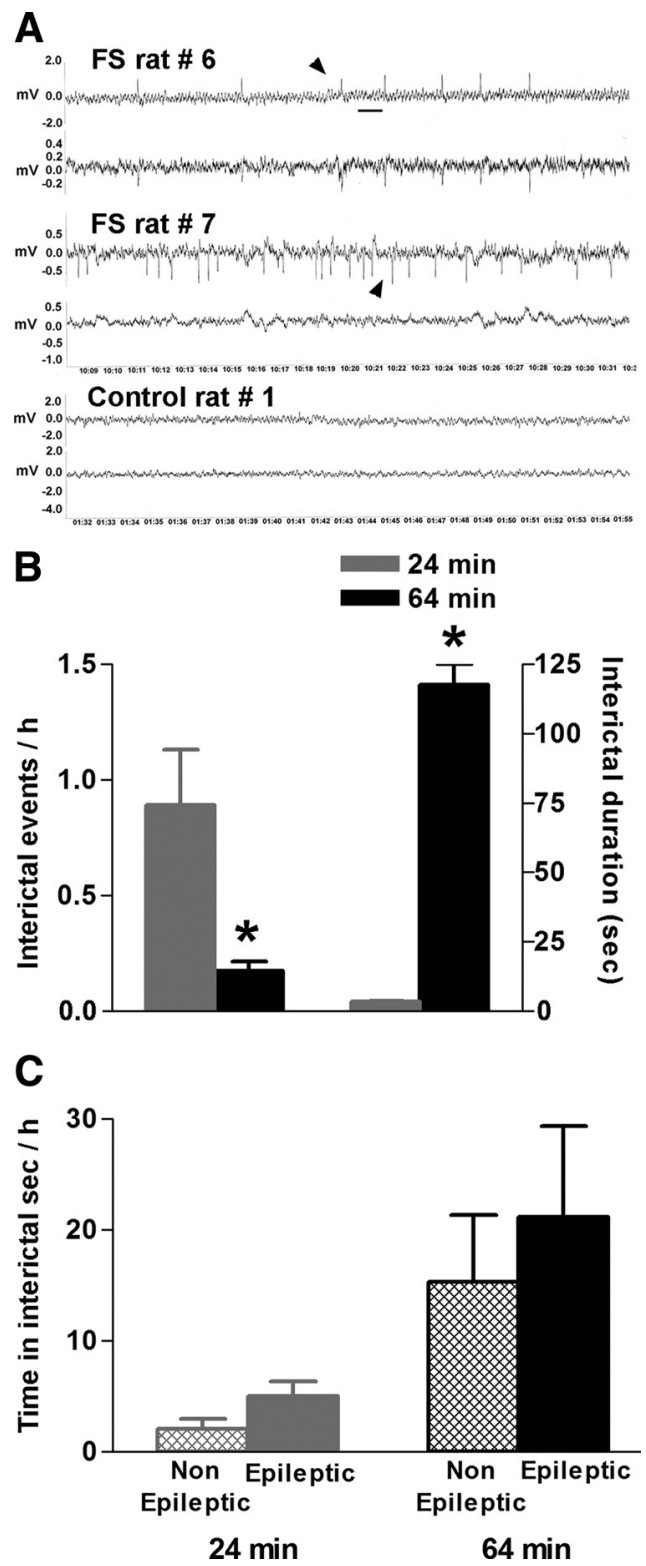

Figure 3. Comparison of the interictal activity recorded from hippocampal electrodes in adult rats that sustained either a $24 \mathrm{~min}$ or a $64 \mathrm{~min}$ FS. $\boldsymbol{A}$, Examples of interictal epileptiform activity (arrowheads), defined as unilateral or bilateral spikes or sharp-waves series after $64 \mathrm{~min}$ FS. These events were never found in control rats. Calibration: 1 s. B, A 64 min FS promoted more discrete epileptiform events per hour of recording compared with a 24 min FS: 0.17 versus 0.9. The mean duration of interictal events after a $64 \mathrm{~min} F \mathrm{~S}$ was drastically longer: $117.5 \pm 7.6 \mathrm{~s}$ ( $n=111$ spike series) vs $3.5 \pm 0.1 \mathrm{~s}$ ( $n=136$ polyspikes or sharp-waves discharges). C, Average total time (in seconds per hour) spent in interictal activity was not different in rats that developed limbic epilepsy compared with those that did not, after a 24 or a 64 min FS. * $p<$ 0.05. Error bars indicate SEM.

destined to become epileptic $(15.3 \pm 6.0 \mathrm{~s} / \mathrm{h})$ compared with those who did not develop spontaneous seizures $(21.1 \pm 8.2 \mathrm{~s} / \mathrm{h})$.

\section{Inflammation and cell loss in the epileptogenic process that follows experimental long FSs}

Searching for candidate mechanisms for the epileptogenic process occurring in a subgroup of rats experiencing experimental FSs and febrile SE, we focused on the cytokine IL- $1 \beta$. In children, studies about CSF elevation of IL- $1 \beta$ and other cytokines are conflicting, with reports of elevations in some studies (Tütüncüoğlu et al., 2001; Haspolat et al., 2002; Virta et al., 2002b) but not in 

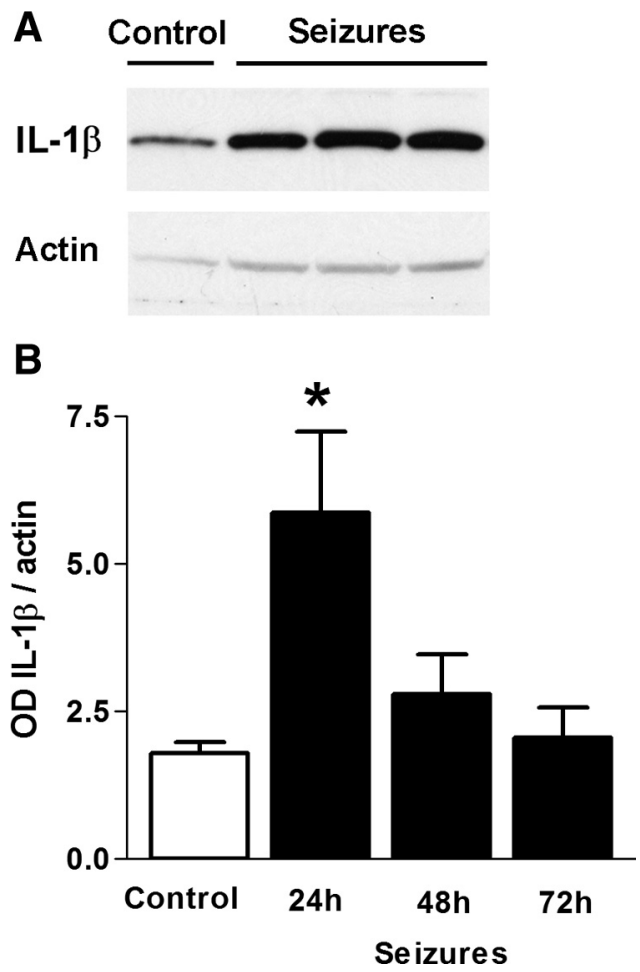

Figure 4. Long (64 min) FS induced enduring IL-1 $\beta$ production in hippocampus. $A, A$ representative Western blot. $\boldsymbol{B}$, Quantitative Western blot analyses of IL-1 $\beta$ protein: $0 D$ of IL-1 $\beta$ immunoreactive bands was normalized to that of actin for each lane and revealed a significant increase $24 \mathrm{~h}$ after long FS. IL- $1 \beta$ levels returned to control levels at $48-72 \mathrm{~h}$. ${ }^{*} p<0.05$. Error bars indicate SEM.

others (Lahat et al., 1997; Ichiyama et al., 1998). Potential explanations for this discrepancy might result from the fact that the children studied had seizures of varying durations, and those who became epileptic were not distinguished from those who did not. In our rodent model of FSs, we have previously found that IL- $1 \beta$ contributed to seizure generation, because mice lacking the IL1RI (IL-1 $\beta$ receptor type I) required higher temperatures to generate seizures (Dubé et al., 2005). However, whereas the involvement of IL- $1 \beta$ signaling in the seizures themselves was established using the transgenic mice, it remained unclear if the seizures induced expression of IL- $1 \beta$ in the brain and if IL- $1 \beta$ contributed to the epileptogenic process that followed these seizures.

We first measured the production of IL- $1 \beta$ protein in hippocampus of immature rats experiencing 64-min-long FSs. As shown in Figure 4, $A$ and $B$, Western blot analyses of hippocampal homogenates harvested $24 \mathrm{~h}$ after FSs demonstrated augmented levels of the cytokine in the FS group compared with controls $(5.88 \pm 1.37$ and $1.8 \pm 0.18$ optical density normalized per actin, respectively; $p=0.04$; $t$ test with Welch's correction for unequal variance). When measured at 48 and $72 \mathrm{~h}$ after the FS, IL-1 $\beta$ levels declined toward control levels, $2.8 \pm 0.67$ at $48 \mathrm{~h}$ $(n=5)$ and $2.1 \pm 0.51$ at $72 \mathrm{~h}(n=8) ; p>0.05$ vs controls. These data indicated that de novo synthesis of IL-1 $\beta$ protein was induced for at least $24 \mathrm{~h}$, with a wide variance in the rate of return of IL- $1 \beta$ levels to baseline among rats (SD of IL- $1 \beta$ protein levels in FS rats at 48-72 h, 2.641; SD of the "basal" levels in controls, 0.128). Thus, augmented hippocampal levels of the cytokine in some rats might persist long enough to initiate molecular cascades that might promote epileptogenesis (Vezzani and Baram, 2007).
We then examined the cells of origin of IL- $1 \beta$ in the hippocampus of rats experiencing long FSs (Fig. 5). Looking at reactive astrocytes expressing GFAP, we found that they were more abundant in FS rats at $6 \mathrm{~h}$ (Fig. $5 C, D)$ and at $24 \mathrm{~h}$ (Fig. 5 E, F ) after the seizures compared with controls, where the morphology of astrocytes was typical for their resting state (Fig. $5 A, B$ ). Scattered OX-42-expressing reactive microglia were more commonly found in FS versus control group at $6 \mathrm{~h}\left(\right.$ Fig. $\left.5 C^{\prime}, D^{\prime}\right)$ and $24 \mathrm{~h}$ (Fig. $5 E^{\prime}, F^{\prime}$ ) after the seizures, although these cells were relatively sparse compared with the astrocytic activation observed in adjacent sections. Widespread expression of IL- $1 \beta$-positive cells was observed at both $6 \mathrm{~h}\left(\right.$ Fig. $\left.5 C^{\prime \prime}, D^{\prime \prime}\right)$ and $24 \mathrm{~h}$ (Fig. $\left.5 E^{\prime \prime}, F^{\prime \prime}\right)$ after FSs, and dual-labeling ICC demonstrated that the activated astrocytes were the source of the increased IL- $1 \beta$ in FS rats (Fig. $5 C^{\prime \prime}-F^{\prime \prime}$, insets). No colocalization between IL- $1 \beta$ and OX-42 signals was observed (data not shown). Together, the above studies provided independent confirmation of the Western blot data (Fig. 4), indicating that IL- $1 \beta$ not only contributed to the FSs themselves (as established by Dubé et al., 2005) but was also induced in astrocytes of FS rats for at least $24 \mathrm{~h}$.

The persistence of IL- $1 \beta$-producing astrocytes in FS rats after the end of the acute "febrile" seizures, and the different decay rates of IL- $1 \beta$ expression in individual rats after the first $24 \mathrm{~h}$ from FS induction, coupled with the development of epilepsy only in a subset of FS rats, raised the question of the potential involvement of this inflammatory mediator in the epileptogenic process. This hypothesis would predict that rats that became epileptic would have more robust inflammation and an augmented IL- $1 \beta$ production compared with rats that did not develop spontaneous seizures. Therefore, we examined hippocampal IL-1 $\beta$ levels in epileptic and nonepileptic FS rats and in controls using Western blot (Fig. 6). We found that IL-1 $\beta$ protein levels in hippocampal homogenates of FS rats with frank seizures $(n=5)$ were significantly higher than those of controls $(n=5)$, whereas levels of rats with interictal activity only $(n=6)$ only were not different from control levels (Fig. 6). These data suggest an involvement of IL-1 $\beta$ in the epileptic process but do not allow us to exclude the possibility that IL- $1 \beta$ elevation was a result of the intermittent seizures experienced by the epileptic rats.

If inflammatory processes contributed to epileptogenesis, how might this happen? Inflammatory cytokines including IL-1 $\beta$ have been shown to contribute to cell injury and death (Allan et al., 2005; Vezzani and Granata, 2005). In a number of animal models, epileptogenesis is associated with loss of select populations of neurons in the hippocampal formation (Ben-Ari, 1985; Sutula et al., 1988; Sloviter, 1994; Pitkänen et al., 2002). Loss of neurons in hippocampal pyramidal cell layers and the dentate gyrus is also typically found in hippocampus of individuals with TLE (Mathern et al., 1997; Bender et al., 2003b). Therefore, having found elevated levels of IL- $1 \beta$, a cytokine known to promote cell injury, in FS rats that became epileptic, we tested if cell loss accompanied, and perhaps accounted for, the epileptogenic process after long FSs. Extensive, blinded counts of cells were performed throughout vulnerable hippocampal regions using stereological principles, and neurons were distinguished from astrocytes using morphological criteria. These measurements failed to demonstrate appreciable loss of neurons in rats that became epileptic compared with those with interictal activity alone, or control rats (Fig. 7). Whereas subtle loss of hilar interneurons could not be excluded using the methods used here, the data suggest that the epileptogenic process that followed prolonged FSs in the rodent model did not require an extensive loss of cells. These data are consistent with the idea that, after febrile 

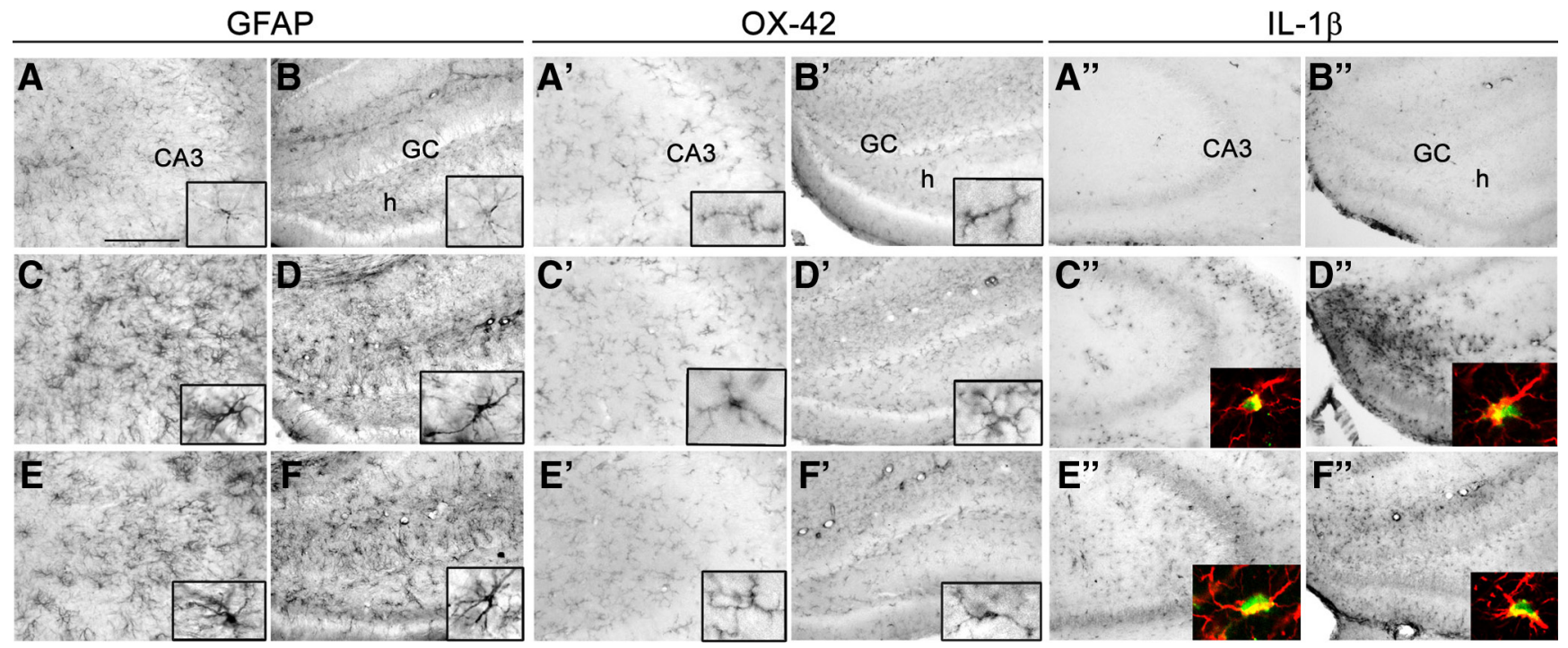

Figure 5. Long ( $64 \mathrm{~min}$ ) FS promoted prominent activation of astrocytes and mild activation of microglia within $24 \mathrm{~h}$ after the seizures. Left panels, Astrocytosis denoted by the hypertrophic cell body and long and thick processes of the astrocytes was evoked 6 and $24 \mathrm{~h}$ after the seizures ( $\boldsymbol{C}-\boldsymbol{F}$ and their insets) compared with the control (A, $\boldsymbol{B}$, and their insets) in $C A 3$ hippocampal area $(\boldsymbol{C}, \boldsymbol{E}$, vs $\boldsymbol{A})$ and in the hilus of the dentate gyrus $(\boldsymbol{D}, \boldsymbol{F}$, vs $\boldsymbol{B})$. Middle panels, 0 X-42 immunoreactivity was detected in resting microglia with small cell body and scant ramification in control rats $\left(\boldsymbol{A}^{\prime}, \boldsymbol{B}^{\prime}\right.$, and their insets). Scattered mildly activated microglial cells (moderate hypertrophic processes) were evident $6 \mathrm{~h}\left(\boldsymbol{C}^{\prime}, \boldsymbol{D}^{\prime}\right.$, and their insets) and $24 \mathrm{~h}\left(\boldsymbol{E}^{\prime}, \boldsymbol{F}^{\prime}\right.$, and their insets) after the onset of FSs. Right panels, IL-1 $\beta$ immunoreactivity was undetectable in control rats $\left(\boldsymbol{A}^{\prime \prime}, \boldsymbol{B}^{\prime \prime}\right)$ and was robust in glial cells $6 \mathrm{~h}\left(\boldsymbol{C}^{\prime \prime}, \boldsymbol{D}^{\prime \prime}\right)$ and $24 \mathrm{~h}\left(\boldsymbol{E}^{\prime \prime}, \boldsymbol{F}^{\prime \prime}\right)$ after seizures. Double immunostaining (yellow in insets) demonstrated that IL-1 $\beta$ (green) protein expression was localized to astrocytes (GFAP; red). Scale bars: $\boldsymbol{A}-\boldsymbol{F}, \boldsymbol{A}^{\prime}-\boldsymbol{F}^{\prime}, \boldsymbol{B}^{\prime \prime}, \boldsymbol{D}^{\prime \prime}, \boldsymbol{F}^{\prime \prime}, 25 \mu \mathrm{m} ; \boldsymbol{A}^{\prime \prime}$, $\boldsymbol{C}^{\prime \prime}, \boldsymbol{E}^{\prime \prime}, 50 \mu \mathrm{m} ; \boldsymbol{A}-\boldsymbol{F}$, insets, $\boldsymbol{A}^{\prime}-\boldsymbol{F}^{\prime}, 12 \mu \mathrm{m} ; \boldsymbol{C}^{\prime \prime}-\boldsymbol{F}^{\prime \prime}$, insets, $10 \mu \mathrm{m}$.
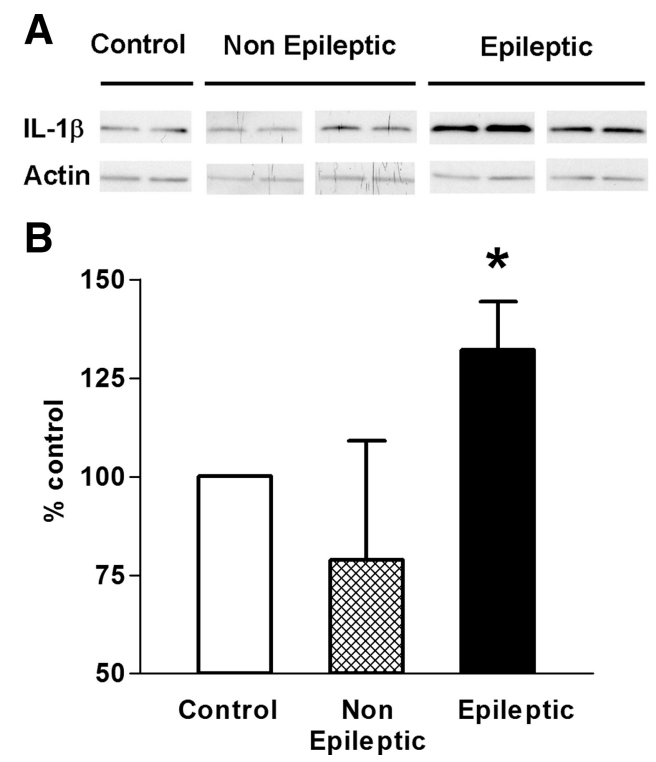

Figure 6. Hippocampal IL-1 $\beta$ protein levels were increased in rats that developed epilepsy after a $64 \mathrm{~min}$ FS compared with those that did not. $A$, A representative Western blot showed enhanced levels of IL-1 $\beta$ protein in rats with epilepsy $(n=5)$ compared with those with interictal activity only $(n=6)$. B, Quantitative Western blot analyses of IL-1 $\beta$ from CA1 hippocampal area: $0 D$ of IL-1 $\beta$-immunoreactive bands was normalized to that of actin for each lane, and the data were expressed as percentage of control. The analyses demonstrated a significant increase of IL-1 $\beta$ protein levels in rats that developed epilepsy. ${ }^{*} p<0.05$. Error bars indicate SEM.

SE in children, the apparent cell loss in hippocampus (mesial temporal sclerosis) might be a result of the ensuing epilepsy, rather than its cause. Together, the above studies of inflammation after long FSs demonstrate an activation of IL- $1 \beta$ in hippocampus in rats experiencing spontaneous seizures, and are consistent with involvement of this cytokine in an epileptogenic process that takes place in the absence of significant neuronal death (Toth et al., 1998). Rather than death, the function of surviving neurons is altered during the epileptogenic process, as discussed below.

\section{The search for noninvasive biomarkers for epileptogenesis after long FSs: MRI}

Whereas IL- $1 \beta$ protein levels and proliferation and activation of glial cells might delineate, and perhaps contribute, to the development of epilepsy in an individual rat (or child), their assessment is difficult and requires invasive tissue analysis. By contrast, MR imaging is noninvasive and can be repeated, and has proven to help in human and animal studies of epileptogenesis (VanLandingham et al., 1998; Roch et al., 2002; Scott et al., 2002; Jupp et al., 2006; Kharatishvili et al., 2007; Hesdorffer et al., 2008; Provenzale et al., 2008). We have previously found MRI T2 signal changes in a subgroup of rats experiencing shorter (24 min duration) experimental FSs (Dubé et al., 2004, 2009). Therefore, here we queried if MRI changes would occur after a $64 \mathrm{~min}$ febrile SE and if such T2 signal changes would help predict the presence of spontaneous seizures (i.e., epilepsy) in individual rats. Hippocampal T2 map analyses of MRI scans obtained a month after a 64 min FS (nine FS and five control rats) yielded results similar to those found in rats experiencing a 24 min FS. Namely, visually apparent, increased hippocampal T2 relaxation times were observed in a subset (six of nine) of FS rats (Fig. $8 A$; $B$, top six values), and these changes were highly asymmetric (as typical in children with febrile SE). Interestingly, hippocampal T2 values in the involved hippocampus in individual FS rats correlated significantly with the total time (seconds/hour) spent in interictal activity (Fig. 8C). However, T2 values did not differ significantly in rats that developed epilepsy after a 64 min FS compared with rats that did not (Fig. 8D), and in individual rats, MRI T2 signal changes did not correlate with epileptogenesis, as defined by the presence of spontaneous seizures. Thus, $42 \%$ of rats with increased hippocampal T2 levels had spontaneous seizures, and $57 \%$ had interictal activity only; $25 \%$ of rats with spontaneous seizures had normal MRI (Spearman's test, $r=0.09$ ). The T2 
A

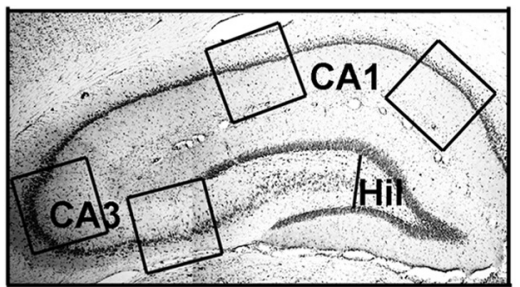

Neuronal Density

B

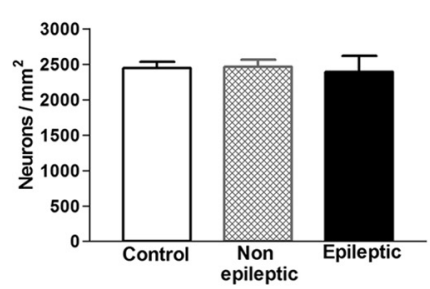

\section{C}

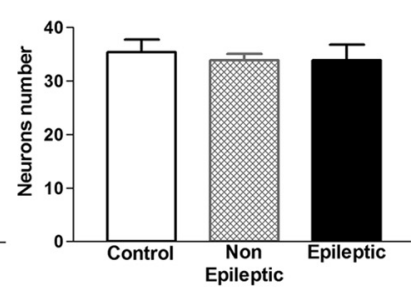

D

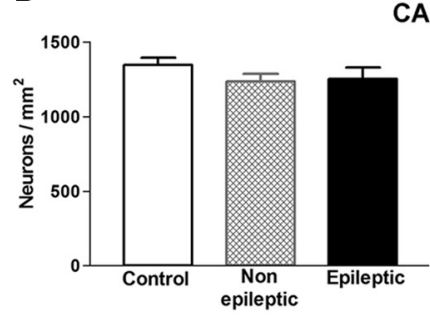

E

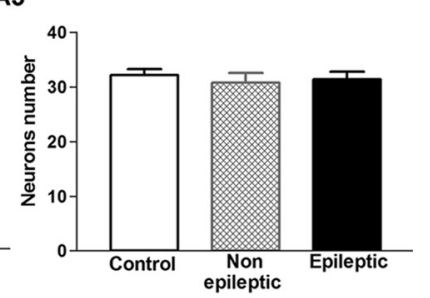

$\mathbf{F}$

G
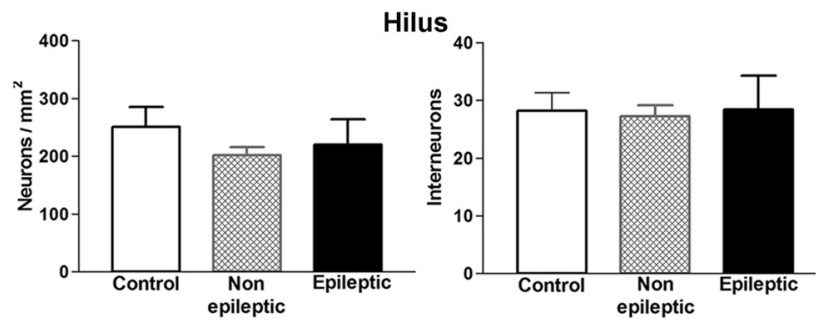

Figure 7. Neuronal density and counts in hippocampal areas most affected in limbic epilepsy did not reveal significant cell loss in epileptic and nonepileptic rats that had experienced a 64 $\min F S$ early in life. $A$, The schematic demonstrates the areas of analysis: CA1 and CA3 pyramidal cell layers and the hilus of dentate gyrus. $\boldsymbol{B}, \mathbf{D}, \boldsymbol{F}$, Neuronal densities in hippocampal areas CA1 and $C A 3$ and in the hilus of the dentate gyrus of the epileptic rats did not differ from the densities of the nonepileptic and control rats ( $n=9)$ (one-way ANOVA, CA1, $p=0.93 ; \mathrm{CA}, p=0.33$; and hilus, $p=0.4) . C, E, G$, In the three regions examined, numbers of neurons were not significantly different in epileptic, nonepileptic, and control rats (one-way ANOVA, CA1, $p=$ $0.82 ; C A 3, p=0.83$; and hilus, $p=0.96$ ). These data suggested that significant loss of neurons was not a prerequisite for the epileptogenic process that followed prolonged FSs. Error bars indicate SEM.

signal abnormalities in MRI obtained 1 month after the FS did not predict the presence of augmented hippocampal levels of IL-1 $\beta$ several months later (Fig. $8 E$ ), although correlation of concurrent inflammation and T2 signal have been reported (Bien et al., 2000).

Together, these findings suggest that MRI changes occur in subset of rats experiencing experimental febrile SE. These changes are asymmetric, are present even 1 month after the seizures, yet do not provide a marker of epileptogenesis. Rather, as found in a cohort experiencing a $24 \mathrm{~min}$ FS, they may denote hippocampal dysfunction manifesting as cognitive defects (Dubé et al., 2009).
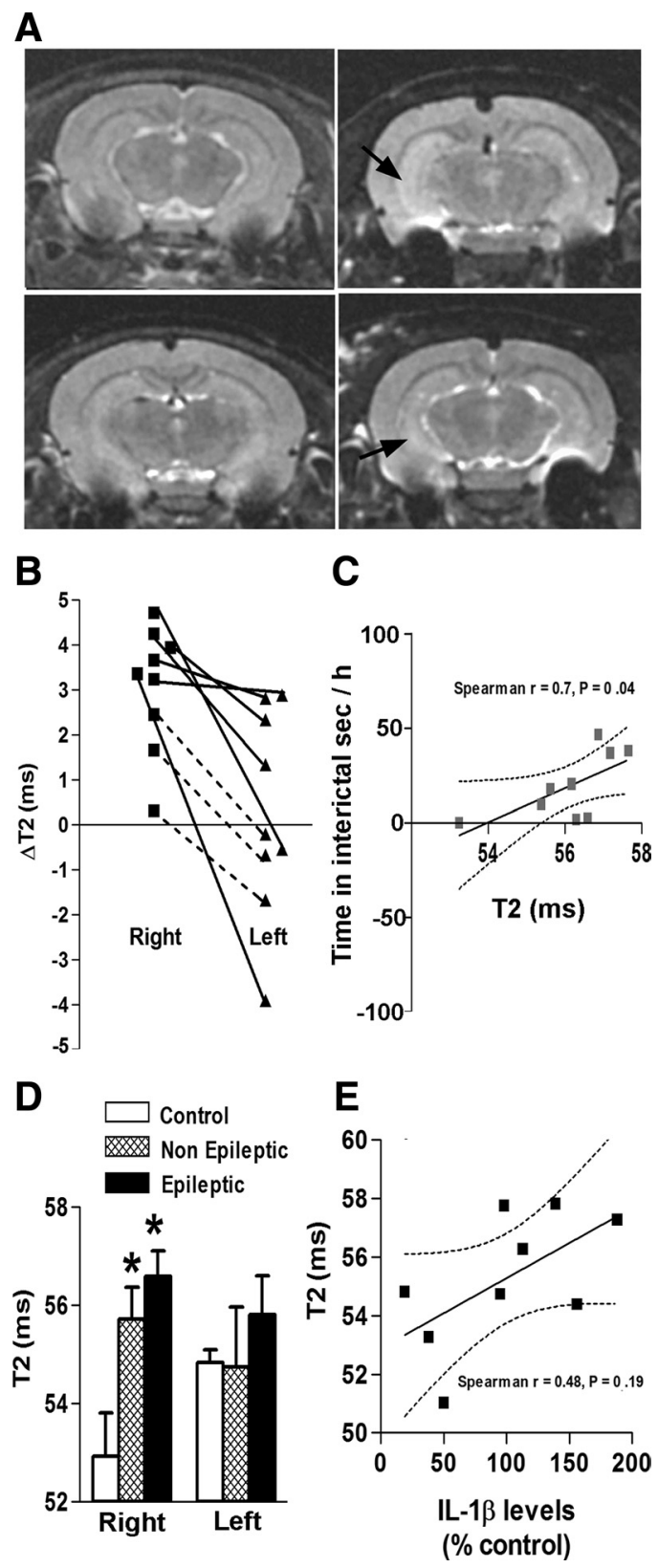

Figure 8. MRI changes did not predict epilepsy. $A$, Examples of T2-weighted images obtained 1 month after a $64 \mathrm{~min}$ FS: increased T2 signal (arrows) in hippocampus of a subset of rats that experienced long FSs (right panels) compared with control rats (leftpanels). B, T2 intensities were quantified by calculating T2 relaxation time values (in milliseconds). T2 values for the right and left hippocampi of each experimental rat were calculated, and the difference from the mean of control rats was determined. This $T 2$ value difference $(\Delta)$ was more robust in the right hippocampus versus the left one, indicating an asymmetry. The plain lines depict rats with increased $\mathrm{T} 2$ relaxation time compared with controls. C, Correlation of hippocampal T2 values with the total time spent in interictal activity for individual experimental rats: The highest $\mathrm{T} 2$ values in the right hippocampus were observed in rats with maximal times spent in interictal activity (Spearman's $r=0.7 ; p=0.04$ ). There was no significant correlation for the lefthippocampus. $\boldsymbol{D}$, Right hippocampal T2 values were significantly higher in three of four epileptic rats and in three of five nonepileptic rats compared with the control rats, but did not differ between epileptic and nonepileptic rats (ANOVA). $\boldsymbol{E}$, There was no significant correlation between left hippocampal T2 values and IL-1 $\beta$ protein levels (Spearman's $r=0.48 ; p=0.19$ ). Error bars indicate SEM. ${ }^{*} p<0.05$.

\section{Discussion}

The major findings of this study are as follows: (1) In an experimental rodent model, the incidence of limbic epilepsy after long FSs and the severity of the spontaneous seizures were influenced 
by the duration of the original FS. (2) Interictal activity in rats experiencing a $64 \mathrm{~min}$ febrile SE was significantly longer and more robust than in that after a 24 min seizure, yet it did not constitute a biomarker for the occurrence of spontaneous seizures. (3) Long FSs led to the activation of astrocytes that produced the inflammatory cytokine IL- $1 \beta$ in a subset of rats, and the latter might be involved in the epileptogenic process. (4) Selective MRI changes, similar to those in children, were observed in hippocampi of a subset of rats experiencing febrile SE; these correlated with interictal EEG activity yet were not predictive of epileptogenesis.

\section{Does the duration of a febrile seizure govern the development and severity of epilepsy?}

Whereas most children experiencing febrile SE do well, some eventually develop epilepsy, yet the reasons for this differential outcome have remained unclear. A large number of potential predisposing factors have been proposed, including ion channel mutations (Berkovic and Scheffer, 1998), cortical dysplasia (Spreafico et al., 2000), and gene polymorphisms (IL-1 $\beta$, SCN1A) (Virta et al., 2002a; Schlachter et al., 2009). Whereas it is possible that these predisposing factors determine which child with febrile SE will develop TLE, finding if there are features of the seizures themselves that predispose to epileptogenesis independent of the host brain is important, helping clinicians to institute measures to avoid long-duration FSs. Animal models enable excluding predisposing host brain factors and systematic analyses of FS characteristics in a controlled and prospective manner. Guided by emerging evidence from the FEBSTAT Study (S. Shinnar, Principal Investigator) that FS duration might contribute to epileptogenesis, we modified our existing model to recapitulate febrile $\mathrm{SE}$, generating seizures lasting $\sim 60 \mathrm{~min}$ without dehydration, resembling long febrile episodes in children. We found that seizure duration influenced epileptogenesis augmenting the severity of the resulting epilepsy, measured by duration of the spontaneous seizures and their generalization (Racine stage).

\section{Significance of EEG interictal activity after febrile status epilepticus}

EEGs of most rats experiencing experimental seizures lasting 24 or 64 min (31 of 36) became abnormal, demonstrating sharpwave bursts, isolated or series of spikes and sharp waves. These events were never observed in controls and very rarely in hyperthermic controls (rats experiencing hyperthermia treated with diazepam or barbiturates to prevent seizures). Whereas the type (sharp wave burst vs spikes series) and duration of interictal activity depended on the duration of the inciting seizures, the significance of these events remains unclear. Because they are never found in naive rats, interictal events might indicate network hyperexcitability and the initial phases of an epileptogenic process. Indeed, interictal events always preceded the seizures in rats that developed spontaneous seizures. However, only $\sim 50 \%$ of rats with interictal activity developed spontaneous seizures during recording epochs of 5-10 months. Whereas we did not perform continuous recordings over this period and thus cannot exclude entirely the presence of seizures, these data suggest that interictal activity can persist for months equivalent of decades in people, without development of overt epilepsy. In previous work, we found that rats experiencing long FSs were more vulnerable to a second excitatory "hit," developing SE in response to kainic acid doses that did not affect controls (Dubé et al., 2000). In addition, electrophysiological studies indicated major proexcitatory changes in their hippocampal circuit, including altered expres- sion of ion channels (Chen et al., 2001; Brewster et al., 2002). Whether a second "hit" would render these rats frankly epileptic is unclear. Thus, the presence of interictal activity denoted long FSs and resulting hyperexcitable limbic circuit. However, they did not reliably predict frank epilepsy.

\section{Inflammation after experimental febrile status epilepticus: significance for epileptogenesis}

We found a significant increase in IL- $1 \beta$ expression within activated astroglial cells in the group of rats experiencing long FSs. We have previously shown that IL- $1 \beta$ was released during the experimental FSs and contributed to the generation of these seizures (Dubé et al., 2005). These new data demonstrate that the seizures also induced the synthesis of the cytokine for a minimum of $24 \mathrm{~h}$ after the seizures. IL-1 $\beta$ has been shown to have potent proconvulsant properties in both immature (Dubé et al., 2005; Heida and Pittman, 2005) and adult (Vezzani et al., 1999, 2000; Balosso et al., 2008) rodents, rendering it a candidate for promoting the epilepsy observed in a subgroup of rats experiencing febrile SE. Because measurements of IL- $1 \beta$ (as well as analysis of reactive astrocytes and microglia) require harvesting the brains, we do not know if the rats that produced more IL- $1 \beta$ at $24 \mathrm{~h}$ after FSs, or that had longer persistence of elevated cytokine levels at 48 or $72 \mathrm{~h}$, were those destined to become epileptic. The presence of significantly higher IL- $1 \beta$ levels in the hippocampi of rats with spontaneous seizures compared with those without frank epilepsy supports, but does not prove this possibility. The mechanisms by which IL- $1 \beta$ and related inflammatory mediators might promote epileptogenesis are not fully understood (Vezzani and Baram, 2007; Vezzani et al., 2008); however, the cellular pathway involved in its proconvulsant effects has recently been demonstrated (Balosso et al., 2008) and may also contribute to persistent changes in neuronal network excitability. Inflammation has classically been considered to promote neuronal damage and death, yet these were not found here (see below). The potential role of IL- $1 \beta$ production after FSs in the epileptogenic process will be addressed in future studies, which will block IL- $1 \beta$ production acutely and examine if this prevents epileptogenesis after febrile SE.

\section{MRI signal change after febrile status epilepticus: not a marker of mesial temporal sclerosis}

We performed MRI using T2-weighted scanning protocols to test if T2 values might indicate hippocampal edema, inflammation, or cell loss, and if they were indicative of an epileptogenic process. Abnormally elevated T2 values were found in a subgroup of FS rats and the pattern of these changes was similar to that found acutely in a subset of children experiencing febrile SE. However, the $\mathrm{T} 2$ changes were not associated with an increased water content of the tissue (C. M. Dubé, unpublished observations), with spontaneous seizures, with significant cell loss, or with significant loss of volume (data not shown). In addition, the higher T2 values, which were prominent in area CA1, were not accompanied by significant cell loss in this region. Whereas subtle loss of some populations of hilar interneurons could not be excluded using the methods used here, detailed blinded cell counts failed to demonstrate a significant overall loss of neuronal populations classically considered vulnerable in hippocampi of rats that developed TLElike epilepsy after experimental febrile SE. These findings are in accord with the absence of significant cell loss in a chemical status epilepticus induced epilepsy model in juvenile rats (Raol et al., 2003). A dissociation of cell loss and epileptogenesis has also been reported in adult rat models (Zhang et al., 2002), indicating that 
loss of vulnerable cells and a resulting circuit reorganization ("sprouting") might not be an absolute requirement for hippocampal epileptogenesis. This lack of appreciable cell loss in rats rendered epileptic by prolonged FSs raises the interesting point of the causal relationship of cell loss and epileptogenesis in humans after long FSs. In individuals with mesial TLE and a history of long FSs, a specific pattern of cell loss in hippocampus [mesial temporal sclerosis (MTS)] is a classical finding. However, the advent of MRI has revealed a significant minority of patients with classical TLE who lack MRI-visible MTS (Mueller et al., 2006). Published studies support both the view that MTS might precede the TLE and perhaps contribute to its onset (VanLandingham et al., 1998; Scott et al., 2003; Provenzale et al., 2008), as well as the alternative view that TLE after FSs might precede MTS, and the latter results from the epileptic seizures (Shinnar, 2003; Salmenperä et al., 2005; Kapur, 2006). The data presented here suggest that the epileptogenic process that follows prolonged FSs in the rodent model does not require extensive cell loss, raising the clinical implication that, after febrile SE in children who do not have preexisting MTS, the MTS found later in their course might be a result of the subsequent TLE, rather than its cause. In this context, MTS might denote a more refractory form of TLE that requires imaging and potentially surgical interventions.

Interestingly, there was a robust correlation (Spearman's $r=$ 0.7 ) between abnormal $\mathrm{T} 2$ values and time spent in interictal activity per hour. This finding is intriguing, because we previously found T2 values to be predictive of hippocampusdependent cognitive deficits, and because the extent of interictal activity correlates with cognitive problems in children and adults (Binnie, 2003; Aldenkamp and Arends, 2004). Together, these findings raise the possibility that augmented T2 values on MRI might indicate ongoing, interictal epileptiform activity, which might impact hippocampus-dependent cognitive functions including declarative memory. These data may prompt clinicians to perform careful cognitive test on children with abnormal T2 signal after febrile SE.

\section{References}

Aldenkamp A, Arends J (2004) The relative influence of epileptic EEG discharges, short nonconvulsive seizures, and type of epilepsy on cognitive function. Epilepsia 45:54-63.

Allan SM, Tyrrell PJ, Rothwell NJ (2005) Interleukin-1 and neuronal injury. Nat Rev Immunol 5:629-640.

Annegers JF, Hauser WA, Shirts SB, Kurland LT (1987) Factors prognostic of unprovoked seizures after febrile convulsions. N Engl J Med 316:493-498.

Ayoub AE, Salm AK (2003) Increased morphological diversity of microglia in the activated hypothalamic supraoptic nucleus. J Neurosci 23:7759-7766.

Balosso S, Maroso M, Sanchez-Alavez M, Ravizza T, Frasca A, Bartfai T, Vezzani A (2008) A novel non-transcriptional pathway mediates the proconvulsive effects of interleukin-1beta. Brain 131:3256-3265.

Baram TZ, Gerth A, Schultz L (1997) Febrile seizures: an appropriate-aged model suitable for long-term studies. Dev Brain Res 98:265-270.

Ben-Ari Y (1985) Limbic seizure and brain damage produced by kainic acid: mechanisms and relevance to human temporal lobe epilepsy. Neuroscience 14:375-403.

Bender RA, Dubé C, Gonzalez-Vega R, Mina EW, Baram TZ (2003a) Mossy fiber plasticity and enhanced hippocampal excitability, without hippocampal cell loss or altered neurogenesis, in an animal model of prolonged febrile seizures. Hippocampus 13:399-412.

Bender RA, Soleymani SV, Brewster AL, Nguyen ST, Beck H, Mathern GW, Baram TZ (2003b) Enhanced expression of a specific hyperpolarizationactivated cyclic nucleotide-gated cation channel (HCN) in surviving dentate gyrus granule cells of human and experimental epileptic hippocampus. J Neurosci 23:6826-6836.

Berg AT, Shinnar S (1996) Complex febrile seizures. Epilepsia 37:126-133. Berg AT, Shinnar S, Hauser WA, Alemany M, Shapiro ED, Salomon ME,
Crain EF (1992) A prospective study of recurrent febrile seizures. N Engl J Med 327:1122-1127.

Berkovic SF, Scheffer IE (1998) Febrile seizures: genetics and relationship to other epilepsy syndromes. Curr Opin Neurol 11:129-134.

Bien CG, Schulze-Bonhage A, Deckert M, Urbach H, Helmstaedter C, Grunwald T, Schaller C, Elger CE (2000) Limbic encephalitis not associated with neoplasm as a cause of temporal lobe epilepsy. Neurology 55:1823-1828.

Binnie CD (2003) Cognitive impairment during epileptiform discharges: is it ever justifiable to treat the EEG? Lancet Neurol 12:725-730.

Brewster A, Bender RA, Chen Y, Dube C, Eghbal-Ahmadi M, Baram TZ (2002) Developmental febrile seizures modulate hippocampal gene expression of hyperpolarization-activated channels in an isoform- and cellspecific manner. J Neurosci 22:4591-4599.

Cendes F, Andermann F, Dubeau F, Gloor P, Evans A, Jones-Gotman M, Olivier A, Andermann E, Robitaille Y, Lopes-Cendes I (1993) Early childhood prolonged febrile convulsions, atrophy and sclerosis of mesial structures, and temporal lobe epilepsy: an MRI volumetric study. Neurology 43:1083-1087.

Chen K, Aradi I, Thon N, Eghbal-Ahmadi M, Baram TZ, Soltesz I (2001) Persistently modified h-channels after complex febrile seizures convert the seizure-induced enhancement of inhibition to hyperexcitability. Nat Med 7:331-337.

Dematte JE, O’Mara K, Buescher J, Whitney CG, Forsythe S, McNamee T, Adiga RB, Ndukwu IM (1998) Near-fatal heat stroke during the 1995 heat wave in Chicago. Ann Intern Med 129:173-181.

Dubé C, Chen K, Eghbal-Ahmadi M, Brunson K, Soltesz I, Baram TZ (2000) Prolonged febrile seizures in the immature rat model enhance hippocampal excitability long-term. Ann Neurol 47:336-344.

Dubé C, Yu H, Nalcioglu O, Baram TZ (2004) Serial MRI after experimental febrile seizures: altered T2 signal without neuronal death. Ann Neurol 56:709-714.

Dubé C, Vezzani A, Behrens M, Bartfai T, Baram TZ (2005) Interleukin1beta contributes to the generation of experimental febrile seizures. Ann Neurol 57:152-155.

Dubé C, Richichi C, Bender RA, Chung G, Litt B, Baram TZ (2006) Temporal lobe epilepsy after experimental prolonged febrile seizures: prospective analysis. Brain 129:911-922.

Dubé CM, Brewster AL, Richichi C, Zha Q, Baram TZ (2007) Fever, febrile seizures and epilepsy. Trends Neurosci 30:490-496.

Dubé CM, Zhou JL, Hamamura M, Zhao Q, Ring A, Abrahams J, McIntyre K, Nalcioglu O, Shatskih T, Baram TZ, Holmes GL (2009) Cognitive dysfunction after experimental febrile seizures. Exp Neurol 215:167-177.

el-Radhi AS, Withana K, Banajeh S (1986) Recurrence rate of febrile convulsion related to the degree of pyrexia during the first attack. Clin Pediatr 25:311-313.

Frantzen E, Lennox-Buchthal M, Nygaard A (1968) Longitudinal EEG and clinical study of children with febrile convulsions. Electroencephalogr Clin Neurophysiol 24:197-212.

French JA, Williamson PD, Thadani VM, Darcey TM, Mattson RH, Spencer SS, Spencer DD (1993) Characteristics of medial temporal lobe epilepsy: I. Results of history and physical examination. Ann Neurol 34:774-780.

Gundersen HJ, Jensen EB (1987) The efficiency of systematic sampling in stereology and its prediction. J Microsc 147:229-263.

Haspolat S, Mihçi E, Coçskun M, Gümüslü S, Ozben T, Yeğin O, Ozbenm T (2002) Interleukin-1beta, tumor necrosis factor-alpha, and nitrite levels in febrile seizures. J Child Neurol 17:749-751.

Hauser W, Hersdorffer D (1990) Epilepsy: frequency, causes and consequences. New York: Demos.

Heida JG, Pittman QJ (2005) Causal links between brain cytokines and experimental febrile convulsions in the rat. Epilepsia 46:1906-1913.

Hesdorffer DC, Chan S, Tian H, Allen Hauser W, Dayan P, Leary LD, Hinton VJ (2008) Are MRI-detected brain abnormalities associated with febrile seizure type? Epilepsia 49:765-771.

Hopkins PM (2000) Malignant hyperthermia: advances in clinical management and diagnosis. Br J Anaesth 85:118-128.

Ichiyama T, Nishikawa M, Yoshitomi T, Hayashi T, Furukawa S (1998) Tumor necrosis factor-alpha, interleukin-1 beta, and interleukin-6 in cerebrospinal fluid from children with prolonged febrile seizures. Comparison with acute encephalitis/encephalopathy. Neurology 50:407-411.

Jardine DS (2007) Heat illness and heat stroke. Pediatr Rev 28:249-258.

Jupp B, Williams JP, Tesiram YA, Vosmansky M, O’Brien TJ (2006) Hip- 
pocampal T2 signal change during amygdala kindling epileptogenesis. Epilepsia 47:41-46.

Kapur J (2006) Is mesial temporal sclerosis a necessary component of temporal lobe epilepsy? Epilepsy Curr 6:208-209.

Kharatishvili I, Immonen R, Gröhn O, Pitkänen A (2007) Quantitative diffusion MRI of hippocampus as a surrogate marker for post-traumatic epileptogenesis. Brain 130:3155-3168.

Lahat E, Livne M, Barr J, Katz Y (1997) Interleukin-1 beta levels in serum and cerebrospinal fluid of children with febrile seizures. Pediatr Neurol 17:34-36.

Mathern GW, Babb TL, Armstrong DL (1997) Hippocampal sclerosis. In: Epilepsy: a comprehensive textbook (Engel J Jr, Pedley TA, eds), pp 133155. Philadelphia: Lippincott-Raven.

Maytal J, Shinnar S, Moshé SL, Alvarez LA (1989) Low morbidity and mortality of status epilepticus in children. Pediatrics 83:323-331.

Mueller SG, Laxer KD, Cashdollar N, Buckley S, Paul C, Weiner MW (2006) Voxel-based optimized morphometry (VBM) of gray and white matter in temporal lobe epilepsy (TLE) with and without mesial temporal sclerosis. Epilepsia 47:900-907.

Nairismägi J, Gröhn OH, Kettunen MI, Nissinen J, Kauppinen RA, Pitkänen A (2004) Progression of brain damage after status epilepticus and its association with epileptogenesis: a quantitative MRI study in a rat model of temporal lobe epilepsy. Epilepsia 45:1024-1034.

Natsume J, Bernasconi N, Miyauchi M, Naiki M, Yokotsuka T, Sofue A, Bernasconi A (2007) Hippocampal volumes and diffusion-weighted image findings in children with prolonged febrile seizures. Acta Neurol Scand Suppl 86:25-28.

Nelson KB, Ellenberg JH (1976) Predictors of epilepsy in children who have experienced febrile seizures. N Engl J Med 295:1029-1033.

Nelson KB, Ellenberg JH (1978) Prognosis in children with febrile seizures. Pediatrics 61:720-727.

Paxinos G, Watson C (1998) The rat brain in stereotaxic coordinates. San Diego: Academic.

Pitkänen A, Nissinen J, Nairismägi J, Lukasiuk K, Grohn OH, Miettinen R, Kaupinen R (2002) Progression of neuronal damage after status epilepticus and during spontaneous seizures in a rat model of temporal lobe epilepsy. Prog Brain 135:67-83.

Portale AA, Mathias RS, Potter DE, Rozansky DR (2002) Kidneys and electrolytes. In: Rudolph's fundamentals pediatrics (Rudolph AM, Kamei RK, Overby KJ, eds), pp 593-645. New York: McGraw-Hill.

Provenzale JM, Barboriak DP, VanLandingham K, MacFall J, Delong D, Lewis DV (2008) Hippocampal MRI signal hyperintensity after febrile status epilepticus is predictive of subsequent mesial temporal sclerosis. AJR Am J Roentgenol 190:976-983.

Racine RJ (1972) Modification of seizure activity by electrical stimulation. II. Motor seizure. Electroencephalogr Clin Neurophysiol 32:281-294.

Raol YS, Budreck EC, Brooks-Kayal AR (2003) Epilepsy after early-life seizures can be independent of hippocampal injury. Ann Neurol 53:503-511.

Ravizza T, Lucas SM, Balosso S, Bernardino L, Ku G, Noé F, Malva J, Randle JC, Allan S, Vezzani A (2006) Inactivation of caspase-1 in rodent brain: a novel anticonvulsive strategy. Epilepsia 47:1160-1168.

Ravizza T, Gagliardi B, Noé F, Boer K, Aronica E, Vezzani A (2008a) Innate and adaptive immunity during epileptogenesis and spontaneous seizures: evidence from experimental models and human temporal lobe epilepsy. Neurobiol Dis 29:142-160.

Ravizza T, Noé F, Zardoni D, Vaghi V, Sifringer M, Vezzani A (2008b) Interleukin converting enzyme inhibition impairs kindling epileptogenesis in rats by blocking astrocytic IL-1beta production. Neurobiol Dis 31:327-333.

Roch C, Leroy C, Nehlig A, Namer IJ (2002) Predictive value of cortical injury for the development of temporal lobe epilepsy in 21-day-old rats: an MRI approach using the lithium-pilocarpine model. Epilepsia 43:11291136.

Rosenberg H, Davis M, James D, Pollock N, Stowell K (2007) Malignant hyperthermia. Orphanet J Rare Dis 2:21.

Salmenperä T, Könönen M, Roberts N, Vanninen R, Pitkänen A, Kälviäinen R (2005) Hippocampal damage in newly diagnosed focal epilepsy: a prospective MRI study. Neurology 64:62-68.

Schlachter K, Gruber-Sedlmayr U, Stogmann E, Lausecker M, Hotzy C, Balzar J, Schuh E, Baumgartner C, Mueller JC, Illig T, Wichmann HE, Lichtner P, Meitinger T, Strom TM, Zimprich A, Zimprich F (2009) A splice site variant in the sodium channel gene SCN1A confers risk of febrile seizures. Neurology 72:974-978.
Scott RC, Gadian DG, King MD, Chong WK, Cox TC, Neville BG, Connelly A (2002) Magnetic resonance imaging findings within 5 days of status epilepticus in childhood. Brain 125:1951-1959.

Scott RC, King MD, Gadian DG, Neville BG, Connelly A (2003) Hippocampal abnormalities after prolonged febrile convulsion: a longitudinal MRI study. Brain 126:2551-2557.

Shinnar S (1998) Prolonged febrile seizures and mesial temporal sclerosis. Ann Neurol 43:411-412.

Shinnar S (2003) Febrile seizures and mesial temporal sclerosis. Epilepsy Curr 3:115-118.

Shinnar S, Hesdorffer DC, Lewis DV, Bello JA, Chan S, Moshe SL, Nordli DR, Pellock JM, Frank LM, Marmarou A, O’Dell C, FEBSTAT Study Team (2007) Correlation of MRI and EEG findings following febrile status epilepticus: results of the FEBSTAT study. Paper presented at 61st Annual Meeting of American Epilepsy Society, Philadelphia, December.

Shinnar S, Hesdorffer DC, Nordli DR Jr, Pellock JM, O’Dell C, Lewis DV, Frank LM, Moshé SL, Epstein LG, Marmarou A, Bagiella E, FEBSTAT Study Team (2008) Phenomenology of prolonged febrile seizures: results of the FEBSTAT study. Neurology 71:170-176.

Sillanpää M, Camfield PR, Camfield CS, Aromaa M, Helenius H, Rautava P, Hauser WA (2008) Inconsistency between prospectively and retrospectively reported febrile seizures. Dev Med Child Neurol 50:25-28.

Sloviter RS (1994) The functional organization of the hippocampal dentate gyrus and its relevance to the pathogenesis of temporal lobe epilepsy. Ann Neurol 35:640-654.

Spreafico R, Tassi L, Colombo N, Bramerio M, Galli C, Garbelli R, Ferrario A, Lo Russo G, Munari C (2000) Inhibitory circuits in human dysplastic tissue. Epilepsia 41 [Suppl 6]:S168-S173.

Stafstrom CE (2002) The incidence and prevalence of febrile seizures. In: Febrile seizures (Baram TZ, Shinnar S, eds), pp 1-25. San Diego: Academic.

Streit WJ, Kreutzberg GW (1987) Lectin binding by resting and reactive microglia. J Neurocytol 16:249-260.

Sutula T, He XX, Cavazos J, Scott G (1988) Synaptic reorganization in the hippocampus induced by abnormal functional activity. Science 239:1147-1150.

Theodore WH, Bhatia S, Hatta J, Fazilat S, DeCarli C, Bookheimer SY, Gaillard WD (1999) Hippocampal atrophy, epilepsy duration, and febrile seizures in patients with partial seizures. Neurology 52:132-136.

Toth Z, Yan XX, Haftoglou S, Ribak CE, Baram TZ (1998) Seizure-induced neuronal injury: vulnerability to febrile seizures in an immature rat model. J Neurosci 18:4285-4294.

Tütüncüoğlu S, Kütükçüler N, Kepe L, Coker C, Berdeli A, Tekgül H (2001) Proinflammatory cytokines, prostaglandins and zinc in febrile convulsions. Pediatr Int 43:235-239.

VanLandingham KE, Heinz ER, Cavazos JE, Lewis DV (1998) Magnetic resonance imaging evidence of hippocampal injury after prolonged focal febrile convulsions. Ann Neurol 43:413-426.

Vezzani A, Baram TZ (2007) New roles for interleukin- $1 \beta$ in the mechanisms of epilepsy. Epilepsy Curr 7:45-50.

Vezzani A, Granata T (2005) Brain inflammation in epilepsy: experimental and clinical evidence. Epilepsia 46:1724-1743.

Vezzani A, Conti M, De Luigi A, Ravizza T, Moneta D, Marchesi F, De Simoni MG (1999) Interleukin-1 $\beta$ immunoreactivity and microglia are enhanced in the rat hippocampus by focal kainate application: functional evidence for enhancement of electrographic seizures. J Neurosci 19:5054-5065.

Vezzani A, Moneta D, Conti M, Richichi C, Ravizza T, De Luigi A, De Simoni MG, Sperk G, Andell-Jonsson S, Lundkvist J, Iverfeldt K, Bartfai T (2000) Powerful anticonvulsant action of IL-1 receptor antagonist on intracerebral injection and astrocytic overexpression in mice. Proc Natl Acad Sci U S A 97:11534-11539.

Vezzani A, Balosso S, Ravizza T (2008) The role of cytokines in the pathophysiology of epilepsy. Brain Behav Immun 22:797-803.

Virta M, Hurme M, Helminen M (2002a) Increased frequency of interleukin-1 $\beta(-511)$ allele 2 in febrile seizures. Pediatr Neurol 26:192-195.

Virta M, Hurme M, Helminen M (2002b) Increased plasma levels of pro- and anti-inflammatory cytokines in patients with febrile seizures. Epilepsia 43:920-923.

Zhang X, Cui SS, Wallace AE, Hannesson DK, Schmued LC, Saucier DM, Honer WG, Corcoran ME (2002) Relations between brain pathology and temporal lobe epilepsy. J Neurosci 22:6052-6061. 